\title{
Stability analysis of a PMSG based Virtual Synchronous Machine
}

\author{
Baruwa Muftau, Meghdad Fazeli, Augustine Egwebe \\ Electrical and Electronics Engineering Department, Swansea University, \\ Swansea, SA1 8EN, UK
}

\begin{abstract}
This paper proposes a Virtual Synchronous Machine (VSM) strategy for Permanent Magnet Synchronous Generator based wind turbines which enables seamless operation in all operating modes. It guarantees Maximum Power Point Tracking in grid-connected operation, Load Following Power Generation in islanded operation and Low Voltage Ride Through capability during faults. To achieve optimal performance in all operating modes, the stability of the VSM is investigated in the event of small and large perturbations. The small-signal stability analysis of the VSM is conducted using a linearized state space model and the impact of the controllers on the dominant modes are derived using participation factor analysis. The transient stability and dynamic performance of the VSM are analyzed using a non-linear model. Based on this analysis, design guidelines and operational limits of the VSM are established. The results of this analysis are validated using time-domain simulations in MATLAB/SIMULINK.

Keywords: Grid-connection, Islanded, LVRT, MPPT, PMSG, VSM.
\end{abstract}

\section{Introduction}

Driven by environmental, technical and economical factors, the grid topology is evolving, from centralized fossil - based power generation to distributed generation from renewable energy sources (RES) [1]. Irrespective of the power generation source, substantial system inertia is required to maintain stability and suppress oscillations due to disturbances on the network. According to National Grid 2], 70\% of the British power system inertia is currently provided by large synchronous generators (SG). However, with the commitment of the UK to reduce $80 \%$ of its greenhouse emission

\footnotetext{
* Corresponding author

Email address: 750340@swansea.ac.uk (Baruwa Muftau)
} 
by 2050 , RES must generate at least $60 \%$ of power demand. This results in a massive reduction in the system inertia, which must be compensated by implementing ancillary infrastructures or integrating RES with control paradigms which offer similar robustness as the SG [3, 4]. In terms of infrastructures, Nguyen et al [5], studied the impact of synchronous condensers (SC) in maintaining the stability of the future grid. A model of the western Danish power system was utilized for the test senario and results confirmed that, the application of SC at strategic locations, adequately damps power system oscillations and improves the frequency stability. Several research works [6, , 7, 8, have corroborated this findings and it has been applied in some HVDC projects [4, 9, to improve grid strength. Despite the benefits that the SC offers, it may not be economically viable for scenarios with $100 \%$ RES. Hence, several research works have been focused on augmenting the control paradigm of RES rather than adding expensive infrastructures to support the grid.

Swing Equation Based Inertial Response control (SEBIR) have been proposed in previous works including [10], 11], 12] to offer synthetic inertia to the grid. SEBIR is achieved by measuring the frequency of the grid and regulating the power output of the RES in proportion to the rate of change of frequency (RoCoF) and the chosen inertia constant $H$. Although SEBIR is capable of reducing the RoCoF, it can introduce noise in the system and significantly reduce the stability margin of the grid [13. Consequently, several algorithms have been proposed inluding [1, 4], 13] [14, 15] for the implementation of the Virtual Synchronous Machine (VSM). The basic idea of the VSM is to derive the desirable characteristics of the SG by reproducing its static and dynamic characteristics on the RES [1, [15. The VSM is expected to operate seamlessly in grid and islanded modes, and provide robust support for the grid in steady state and fault conditions. Zhong et al. 1], 14], proposed a VSM strategy, which is implemented using the detailed mathematical model of the SG. This VSM offers the same dynamics as the SG, from the grid point of view and is also termed as a synchronverter. It is equipped with frequency and voltage droop control loops which allow for parallel operation of multiple units. Although the synchronverter is able to support the grid, it also exhibits some of the undesirable characteristics of the SG, i.e., hunting phenomena 11. In additon, the complex mathematical computations required for implementation may lead to numerical instability [16]. In [13, a zero inertia VSM control termed as VSM0H was proposed. The adopted topology is similar to the conventional droop control. However, it does not have any inner current loop. The frequency and voltage are regulated in proportion to the active and reactive power demand respectively. The VSM0H is designed with a small control bandwidth (less than $50 \mathrm{~Hz}$ ) to 
minimize voltage harmonics. Although the VSM0H is not equipped with synthetic inertia, it has a fast acting frequency droop slope. The capability of the VSM0H to operate in a scenario of $100 \%$ RES penetration was observed. However, its fault ride through capability was not investigated and the authors confirmed further work is required to verify its viability. An improvement on the VSM0H was proposed in [4 to add a synthetic inertia into the VSM0H, however this causes the system to resonate around certain frequencies $(2-5 \mathrm{~Hz})$. Liu et al [17] proposed a control paradigm to improve the performance of the VSM. It employs a virtual inductance to reduce the active power oscillation and an inverse voltage droop to minimize the reactive power sharing error. Although test results confirm reduced active power oscillations, the output voltage becomes more oscillatory. A common drawback of the VSM design in [1, [4, [13, [14, 17] is the absence of a dedicated current loop, which makes the VSM vulnerable to undesirable current excursions in the event of large disturbances and fault. Hirase et al [18, sought to overcome this by proposing a VSM strategy based on the algebraic model of the SG. It mimics the steady state operation of the SG using phasor diagrams, while the dynamic equations are neglected. The conventional d-q current control loop [19] is implemented here, and the VSM closely mimics the inertia and AVR response of the SG. However, this system requires switching of controllers during transition from grid to islanded mode, which may undermine the seamless operation of the system especially in cases of fault.

In most of the previous works discussed above, the required guidelines for designing and tuning the controllers have not been discussed. From a stability point of view, this information is very crucial, as improper tuning of controllers can lead to oscillatory response and undermine the overall grid stability. In addition, details of the energy source (e.g. wind or solar) were omitted. Hence, energy management issues such as Maximum Power Point Tracking (MPPT) in grid-connected mode, and Load Following Power Generation (LFPG) in islanded mode cannot be investigated.

The VSM strategy proposed in this paper enables (1) Seamless transition from grid-connected to islanded operation and vice versa (2) MPPT and LFPG in grid-connected and islanded modes, respectively (3) Low Voltage Ride Through (LVRT) capability during faults (4) Easy application to industrial standard $d-q$ current control approach minimizing the required changes. The base concept of the VSM employed in this paper is explained in [19] (for a PV system), where it was demonstrated that a virtual governor and a virtual Automatic Voltage Regulator (AVR) can be emulated by a first-order low pass filter. The current paper, proposes a method to adopt the VSM for Permanent Magnet Synchronous Generator (PMSG) based wind systems. 


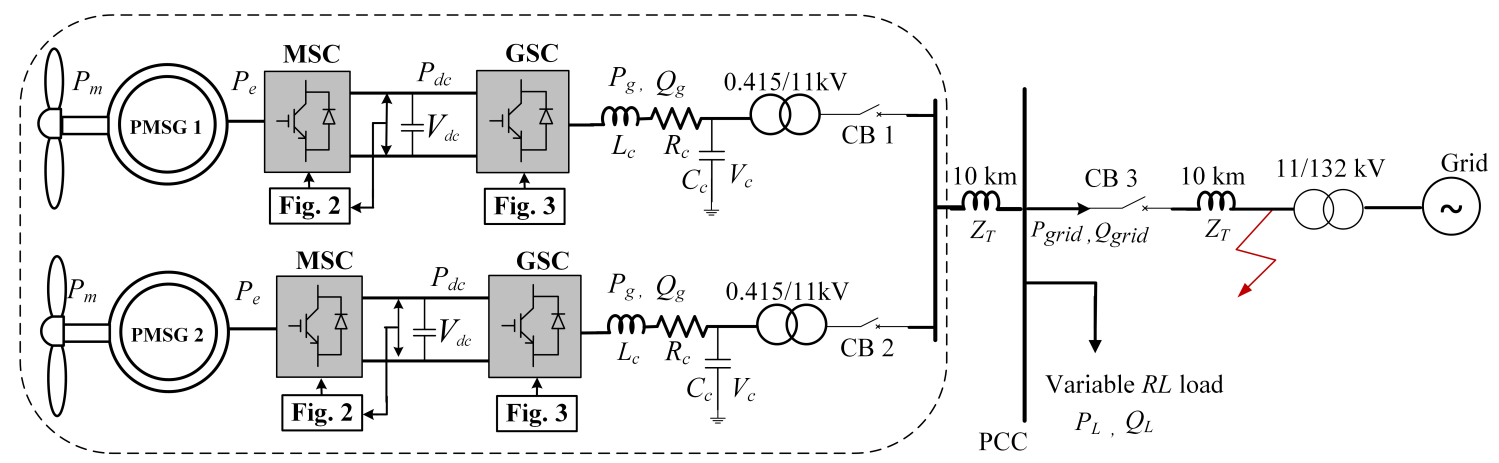

Figure 1: Topology of the understudy system

The other contributions of this paper are:

I) Developing a detailed mathematical model of the proposed VSM.

II) Comprehensive analysis of the VSM in the event of small and large perturbations.

III) Establishing design guidelines using the developed small-signal model.

Since this work is mainly concentrated on the stability analysis of the proposed VSM, in order to avoid mixing it with an energy management system, the following assumptions are made:

(1) The combined turbine and generator inertia is sufficient to damp network disturbances. However, the system can be augmented with an external energy storage (to provide extra support), which is not considered in this paper (for the above reason). (2) During islanding, load power $P_{L}$ $\leq$ total available wind power, and load reactive power $Q_{L} \leq$ available capacity. This paper is organized as follows: A comprehensive description of the proposed control structure and small-signal model is presented in Section II. The eigenvalue analysis and transient performance are discussed in Section III. Section IV presents the simulation results which corroborate the analysis in III. Section $\mathrm{V}$ concludes the findings of this paper and future work.

\section{Modelling of PMSG}

The proposed VSM will be explained for PMSG based wind turbines, however it is applicable to other RES. The topology of the understudy system is illustrated in Fig. 1 .

\subsection{Machine Side Converter}

The Machine Side Converter (MSC) regulates the electrical power $P_{e}$ that the PMSG extracts from the wind turbine. The PMSG is controlled in the $d-q$ frame with the $d$-axis aligned with the 


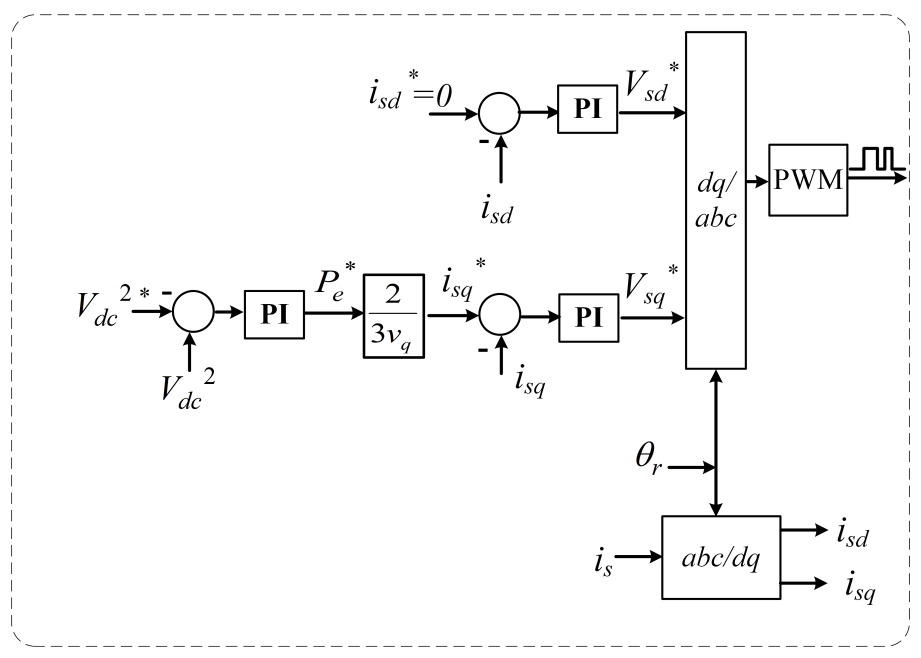

Figure 2: Control structure of the Machine Side Converter

rotor magnetic flux $\lambda_{m}$. The dynamics of the PMSG in the rotor field coordinates is given below [9], 20]:

$$
\begin{aligned}
V_{s d} & =L_{d} \frac{d i_{s d}}{d t}+R_{s} i_{s d}-L_{q} \omega_{r} i_{s q} \\
V_{s q} & =L_{q} \frac{d i_{s q}}{d t}+R_{s} i_{s q}+L_{d} \omega_{r} i_{s d}+\lambda_{m} \omega_{r} \\
J \frac{\omega_{r}}{d t} & =T_{m}-T_{e}-B \omega_{r} \\
\frac{\theta_{r}}{d t} & =\omega_{r}
\end{aligned}
$$

Where $V_{s d}, V_{s q}, i_{s d}, i_{s q}, L_{d}, L_{q}$ represents the $d-q$ component of the stator terminal voltages, current, and self-inductances respectively. $R_{s}, T_{m}, T_{e}, J, B, \omega_{r}$ and $\theta_{r}$ represents the stator resistance, mechanical torque, electromagnetic torque, machine inertia, friction coefficient, rotor speed and rotor angle respectively. For non-salient surface mounted PMSG $\left(L_{q}=L_{d}\right)$ the components of $T_{e}$ are represented by (5), while $P_{e}$ is given by (6) [9]:

$$
\begin{aligned}
T_{e} & =\frac{3}{2} \lambda_{m} i_{s q} \\
P_{e} & =\frac{3}{2} V_{s q} i_{s q}
\end{aligned}
$$

Conventionally, MSC is used to extract the maximum power from the wind and the Grid Side Converter (GSC) transfers the energy to the grid by keeping the DC-link voltage $V_{d c}$ constant. It is well-known that extracting the maximum power from the wind, irrespective of the grid condition, 
can lead to instability 21, 222. E.g. during faults, where the power output of the GSC is attenuated, the excess $P_{e}$ leads to rapid rise in $V_{d c}$ and eventual loss of stability [21. In order to take the grid condition into account, the proposed VSM algorithm in (Fig 3 is used. Applying the VSM algorithm using the conventional structure (i.e. GSC controls $V_{d c}$ ) necessitates separating the virtual AVR (on the GSC) and the virtual Governor (on the MSC). Therefore, to keep the virtual AVR and Governor on one converter, this paper proposes to control $V_{d c}$ by the MSC, while the GSC determines the power imposed on the wind turbine $P_{g}$. Using the proposed structure (Fig 3 ), under normal/strong-grid condition, since $i_{d-f}=0$, the maximum power will be extracted through the MPPT component $i_{d-M P P T}$. In the event of abnormal conditions (e.g. a fault on the grid), the virtual governor will regulate the imposed power on the wind turbine (by adding $i_{d-f}$ to $i_{d-M P P T}$ ). Since MSC makes $P_{e} \approx P_{g}$ (by keeping $V_{d c}$ constant), no supplementary devices will be required to dump the extra energy [22]. The surplus energy from the wind during abnormal conditions will be stored as kinetic energy in the rotor of the wind turbine [21, 222]. Hence, the combination of the wind turbine and associated controls on the MSC, mimics the prime mover of a conventional $\mathrm{SG}$, allowing the contribution of its inertial energy to mitigate system disturbances and suppress oscillations. The relationship between $P_{e}$ and $P_{g}$ is governed by the power balance principle (7), neglecting losses [9]:

$$
P_{e}-P_{g}=C V_{d c} \frac{d V_{d c}}{d t}
$$

Where $C$ represents the DC-link capacitor, $V_{d c}$ is regulated by comparing the reference DC-link voltage $V_{d c}{ }^{2 *}$ with $V_{d c}{ }^{2}$ (see Fig. 2). The error signal is processed by the PI controller to generate

$P e^{*}$ (where $P_{e}^{*} \cong P_{e}$ ), which is then transformed to the equivalent current magnitude $i_{s q}$. The $d$-component of the current is regulated to zero to maximize available power and minimize ohmic losses [9, 23].

\subsection{Grid Side Converter}

The proposed scheme for the VSM is implemented on the GSC, which interfaces with the grid network. It regulates power exchange and ensures stable operation of the PMSG and connected loads in all operating modes. The salient feature of this VSM paradigm is that no switching operation is required in all modes of operation. It employs a single control paradigm, which enables MPPT in grid-connected operation (assuming a strong grid), LFPG in islanded mode and LVRT 


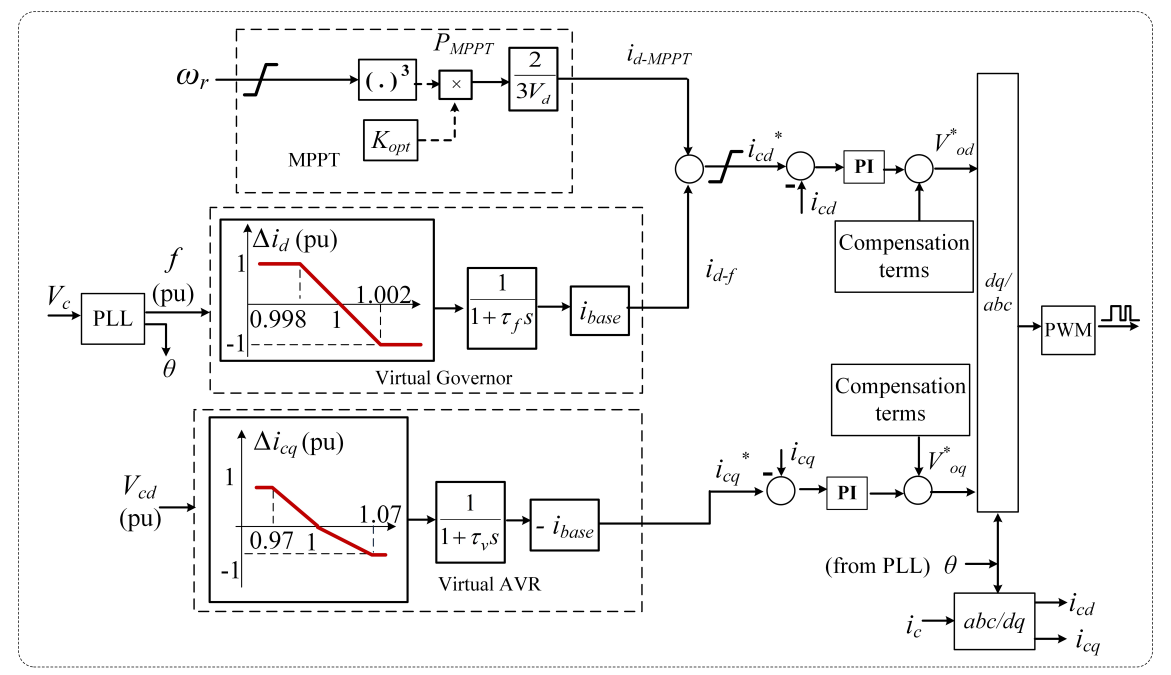

Figure 3: Proposed Control paradigm of the Virtual Synchronous Machine for the Grid Side Converter during faults. This scheme can also support weak grids and provide black start. In order to perform the stability analysis, the system can be divided into four sub-systems: Power synchronization, Power Management System (PMS), current controller, the output filter and load. The operation and small-signal model of each sub-systems are detailed below:

\subsubsection{Power synchronization}

The PLL tracks the phase angle of the filter capacitor voltage $V_{c}$ (Fig. 1) to achieve synchronization with the grid. This ensures the voltage magnitude $V$ is locked with the $d$-axis, $V_{c d} \approx 1 \mathrm{pu}$ and $V_{c q} \approx 0$ [24]. In this scheme, the PLL is used in both grid and islanded modes [19]. The PLL dynamics may be neglected for stiff grids, however they play a crucial role on the system stability for weak grids and islanded operation [25, [26]. The synchronously-rotating-frame (SRF) PLL is implemented in this study [19]. The equations representing the PLL dynamics is given by (8):

$$
\begin{aligned}
\omega & =\omega_{0}+K_{i} \alpha_{P L L}+K_{p} V_{c q} \\
\alpha_{P L L} & =\int V_{c q} d t, \quad \delta=\int \omega d t
\end{aligned}
$$

Where $\alpha_{P L L}$ is the state variable representing $\int V_{c q} d t$. The proportional and integral gains are represented by $K_{p}$ and $K_{i}$ respectively. $\delta$ represents the angle of the inverter $d$ - $q$ frame, $\omega$ and $\omega_{0}$ represent the measured and reference angular frequency respectively. The measured frequency is represented by $f$. By linearizing, the small-signal model can be written in state space as below: 


$$
\begin{aligned}
{\left[\begin{array}{c}
\dot{\Delta \delta} \\
\dot{\alpha_{P L L}}
\end{array}\right] } & =A_{P L L}\left[\begin{array}{c}
\Delta \delta \\
\Delta \alpha_{P L L}
\end{array}\right]+B_{P L L}\left[\Delta V_{c q}\right] \\
{\left[\begin{array}{c}
\Delta \delta \\
\Delta f
\end{array}\right] } & =C_{P L L}\left[\begin{array}{c}
\Delta \delta \\
\Delta \alpha_{P L L}
\end{array}\right]+D_{P L L}\left[\Delta V_{c q}\right] \\
A_{P L L} & =\left[\begin{array}{cc}
0 & K_{i} \\
0 & 0
\end{array}\right], B_{P L L}=\left[\begin{array}{c}
K_{p} \\
1
\end{array}\right] \\
C_{P L L} & =\left[\begin{array}{cc}
1 & 0 \\
0 & \frac{K_{i}}{2 \pi}
\end{array}\right], D_{P L L}=\left[\begin{array}{c}
0 \\
\frac{K_{p}}{2 \pi}
\end{array}\right]
\end{aligned}
$$

\subsubsection{Power Management System}

The PMS, regulates the frequency $f$ and voltage $V$ of the system within nominal value. Since large wind farms are normally connected at transmission level, where the system is mainly inductive, the conventional droop control is used in this paper. Although, it is demonstrated in [27 that conventional droop control can still be used at distribution level, where the system is mainly resistive. The proposed VSM can be modified by supplementary controls, e.g. [28 and [29, to be used in resistive networks (which is beyond the scope of this paper). The main components of the PMS include: virtual AVR, virtual governor and the MPPT. The control structure of the PMS is illustrated in Fig. 3

i) Virtual AVR: The primary function of the virtual AVR is to regulate $V$. In grid connected operation $V$ is maintained by the grid ( $V_{c d} \approx 1 \mathrm{pu}$ ). However, in islanded mode of operation, $V_{c d}$ is regulated in proportion to the current demand $i_{c q}$ (which is associated to reactive load $Q_{L}$ ) as illustrated in Fig. 3 and described in 11. where $V_{c d}^{*}$ is the reference voltage, $i_{c q}^{*}$ is the reference reactive current, while $K_{v}$ and $\tau_{v}$ are the droop gains and damping filter time constant respectively.

$$
i_{c q}^{*}=-K_{v}\left(V_{c d}^{*}-V_{c d}\right)\left(\frac{1}{1+\tau_{v} s}\right)
$$

ii) Virtual Governor and MPPT: The role of the virtual governor in this scheme, is to regulate $f$ within the nominal value. In grid connected mode, $f$ is dictated by the grid network. In islanded operation, $f$ is regulated in proportion to the current demand $i_{d}$ (which is associated to active load $P_{L}$ ). Fig. 3 illustrates the $i_{d}-f$ droop, explained in 12 [19]. It is known that $P_{M P P T}=K_{o p t} \omega_{r}^{3}$, where $\omega_{r}$ is the rotor speed and $K_{o p t}$ is a constant denoting the optimal ratio required between $\omega_{r}$ and $P_{e}$ to achieve MPPT. The integration of the virtual governor and the MPPT loops ensures that maximum power is extracted when 
connected to a stiff grid, and in islanding it follows the load demand without the immediate need of pitch control. Obviously, if $P_{L}$ is very small and wind speed is very high, $\omega_{r}$ may exceed the rated speed (normally $1.2 \mathrm{pu}$ ), which necessitates using the pitch angle. The equation representing the dynamics of the virtual governor and MPPT is given by 12 :

$$
i_{c d}^{*}=K_{f}\left(f^{*}-f\right)\left(\frac{1}{1+\tau_{f} s}\right)+i_{d-M P P T}
$$

Where $f^{*}, i_{c d}^{*}$ and $i_{d-M P P T}$ are the reference frequency, reference active current and output current of the MPPT respectively. $K_{f}$ and $\tau_{f}$ are the droop gains and the damping filter time constant of the virtual governor respectively. Assuming $i_{d-M P P T}$ is constant $\left(d i_{d-M P P T} / d t=0\right)$, the small-signal linearized model of the PMS is given by 13 and 14 :

$$
\begin{aligned}
{\left[\begin{array}{c}
\Delta \dot{i}_{c q}^{*} \\
\Delta \dot{i}_{c d}^{*}
\end{array}\right]=} & A_{P M S}\left[\begin{array}{c}
\Delta i_{c q}^{*} \\
\Delta i_{c d}^{*}
\end{array}\right]+\left[\begin{array}{l}
B_{P M S_{v}} \\
B_{P M S_{f}}
\end{array}\right]\left[\begin{array}{l}
\Delta V_{c d}^{*} \\
\Delta f^{*}
\end{array}\right] \\
& +\left[\begin{array}{c}
B_{P M S_{v}} \\
B_{P M S_{f}}
\end{array}\right]\left[\begin{array}{c}
-\Delta V_{c d} \\
-\Delta f
\end{array}\right] \\
& {\left[\begin{array}{l}
\Delta i_{c q}^{*} \\
\Delta i_{c d}^{*}
\end{array}\right]=C_{P M S}\left[\begin{array}{c}
\Delta i_{c q}^{*} \\
\Delta i_{c d}^{*}
\end{array}\right] }
\end{aligned}
$$

where,

$$
\begin{gathered}
A_{P M S}=\left[\begin{array}{cc}
\frac{-1}{\tau_{v}} & 0 \\
0 & \frac{-1}{\tau_{f}}
\end{array}\right], B_{P M S_{v}}=\left[\begin{array}{cc}
\frac{-K_{v}}{\tau_{v}} & 0
\end{array}\right] \\
B_{P M S_{f}}=\left[\begin{array}{ll}
0 & \frac{K_{f}}{\tau_{f}}
\end{array}\right] \quad, \quad C_{P M S}=\left[\begin{array}{ll}
1 & 0 \\
0 & 1
\end{array}\right]
\end{gathered}
$$

\subsubsection{Current Controller}

The output of the PMS is fed directly to the current controllers as shown in Fig. 2. The current controller shapes the voltage across the filter inductor and dampens oscillations at the output of the $L C$ filters [30, 31]. The equations representing the current controller are given below:

$$
\begin{gathered}
\text { Let } \gamma_{d}=\int i_{c d}^{*}-i_{c d}, \gamma_{q}=\int i_{c q}^{*}-i_{c q} \\
V_{o d}^{*}=-\omega_{0} L_{c} i_{c q}+K_{p c}\left(i_{c d}^{*}-i_{c d}\right)+K_{i c} \gamma_{d} \\
V_{o q}^{*}=\omega_{0} L_{c} i_{c d}+K_{p c}\left(i_{c q}^{*}-i_{c q}\right)+K_{i c} \gamma_{d}
\end{gathered}
$$


Where $\gamma_{d}$ and $\gamma_{q}$ are the state variables in the current controller. The proportional and integral gains are represented by $K_{p c}$ and $K_{i c}$ respectively. $L_{c}$ is the filter inductance, while $V_{o d}^{*}$ and $V_{o q}^{*}$ represents the output voltage of the inverter. The linearized small-signal state space form of the current controller are given below:

$$
\left[\Delta \dot{\gamma}_{d q}\right]=[0]\left[\Delta \gamma_{d q}\right]+B_{C 1}\left[\Delta i_{c d q}^{*}\right]+B_{C 2}\left[\begin{array}{c}
\Delta i_{c d q} \\
\Delta V_{c d q} \\
\Delta i_{l d q}
\end{array}\right]
$$

where $\Delta \gamma_{d q}=\left[\begin{array}{ll}\Delta \gamma_{d} & \Delta \gamma_{q}\end{array}\right]^{T}$

$$
\begin{aligned}
& B_{C 1}=\left[\begin{array}{ll}
1 & 0 \\
0 & 1
\end{array}\right], B_{C 2}=\left[\begin{array}{cccccc}
-1 & 0 & 0 & 0 & 0 & 0 \\
0 & -1 & 0 & 0 & 0 & 0
\end{array}\right] \\
& {\left[V_{o d q}^{*}\right]=C_{c}\left[\Delta \gamma_{d q}\right]+D_{c 1}\left[\Delta i_{c d q}^{*}\right]+D_{c 2}\left[\begin{array}{c}
\Delta i_{c d q} \\
\Delta V_{c d q} \\
\Delta i_{l d q}
\end{array}\right]} \\
& C_{c}\left[\begin{array}{cc}
K_{i c} & 0 \\
0 & K_{i c}
\end{array}\right], D_{c 1}=\left[\begin{array}{cc}
K_{p c} & 0 \\
0 & K_{p c}
\end{array}\right] \\
& D_{c 2}=\left[\begin{array}{cccccc}
-K_{p c} & -\omega_{0} L_{f} & 0 & 0 & 0 & 0 \\
\omega_{0} L_{f} & -K_{p c} & 0 & 0 & 0 & 0
\end{array}\right]
\end{aligned}
$$

\subsubsection{Output LC filter and load}

The output current $i_{c d}$ and $i_{c q}$ from the inverter is fed to the load and grid through the output filters $R_{c}, L_{c}$ and $C_{c}$ of the inverter and coupling inductance. In the small-signal model, the coupling inductance are superimposed with variable load $\left(R_{l}\right.$ and $L_{l}$ in Fig. 1). It is also assumed that the inverter delivers the required output voltage, i.e., $V_{o d q}^{*}=V_{o d q}$. The state equation of the output $L C$ filter and the load are explained below: 


$$
\begin{aligned}
\frac{d i_{c d}}{d t} & =\frac{-R_{c}}{L_{c}} i_{c d}+\omega i_{c q}+\frac{1}{L_{c}} V_{o d}-\frac{1}{L_{c}} V_{c d} \\
\frac{d i_{c q}}{d t} & =\frac{-R_{c}}{L_{c}} i_{c q}-\omega i_{c d}+\frac{1}{L_{c}} V_{o q}-\frac{1}{L_{c}} V_{c q} \\
\frac{d v_{c d}}{d t} & =\omega V_{c q}+\frac{1}{C_{c}} i_{c d}-\frac{1}{C_{c}} i_{l d} \\
\frac{d v_{c q}}{d t} & =-\omega V_{c d}+\frac{1}{C_{c}} i_{c q}-\frac{1}{C_{c}} i_{l q} \\
\frac{d i_{l d}}{d t} & =\frac{-R_{l}}{L_{l}} i_{l d}+\omega i_{l q}+\frac{1}{L_{l}} V_{c d} \\
\frac{d i_{l q}}{d t} & =\frac{-R_{l}}{L_{l}} i_{l q}-\omega i_{l d}+\frac{1}{L_{l}} V_{c q}
\end{aligned}
$$

The linearized small-signal state space form of the $L C$ filter and load is given by:

$$
\begin{aligned}
& A_{L C L}=\left[\begin{array}{cccccc}
\frac{-R_{c}}{L_{c}} & \omega_{0} & \frac{-1}{L_{c}} & 0 & 0 & 0 \\
-\omega_{0} & \frac{-R_{c}}{L_{c}} & 0 & \frac{-1}{L_{c}} & 0 & 0 \\
\frac{1}{C_{c}} & 0 & 0 & \omega_{0} & \frac{-1}{C_{c}} & 0 \\
0 & \frac{1}{C_{c}} & -\omega_{0} & 0 & 0 & \frac{-1}{C_{c}} \\
0 & 0 & \frac{1}{L_{l}} & 0 & \frac{-R_{l}}{L_{l}} & \omega_{0} \\
0 & 0 & 0 & \frac{1}{L_{l}} & -\omega_{0} & \frac{-R_{l}}{L_{l}}
\end{array}\right] \\
& B_{L C L 1}=\left[\begin{array}{cccccc}
\frac{1}{L_{l}} & 0 & 0 & 0 & 0 & 0 \\
0 & \frac{1}{L_{l}} & 0 & 0 & 0 & 0
\end{array}\right]^{T} \\
& B_{L C L 2}=\left[\begin{array}{llllll}
i_{c q} & -i_{c d} & V_{c q} & -V_{c d} & i_{l q} & -i_{l d}
\end{array}\right]^{T} \\
& {\left[\begin{array}{c}
\Delta i_{c d q} \\
\Delta \dot{V}_{c d q} \\
\Delta \dot{i}_{l d q}
\end{array}\right]=A_{L C L}\left[\begin{array}{c}
\Delta i_{c d q} \\
\Delta V_{c d q} \\
\Delta i_{l d q}
\end{array}\right]+B_{L C L 1}\left[\Delta V_{o d q}\right]+B_{L C L 2}[\Delta \omega]}
\end{aligned}
$$

The overall linearized model of the system is illustrated in Fig. 4 The aggregated matrix, is derived by combining the state space models of the Power synchronization sub-system 9 PMS 13,14 current controller 120 19, 21 the output filter and load 30, 31, 32, 333 and is detailed in the Appendix A 


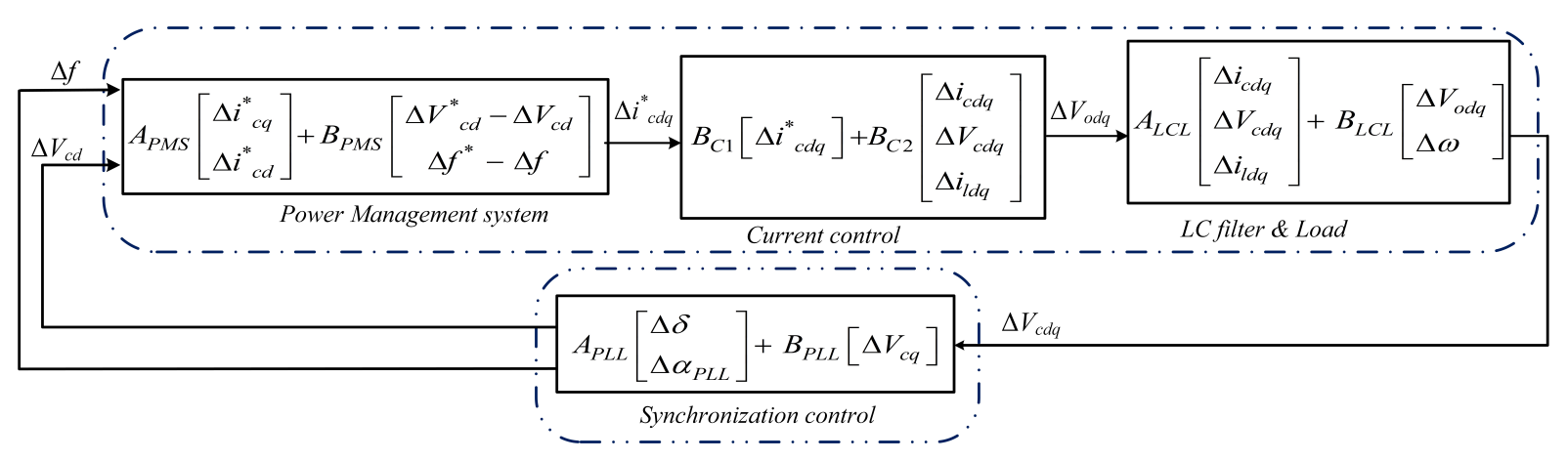

Figure 4: Linearized model of the proposed VSM

\section{Stability Analysis and Dynamic Peformance of the Proposed VSM}

The stability of the proposed VSM, will be analyzed for both small and large perturbations. In this section, the MSC is replaced by a constant DC source in order to focus on the VSM dynamics.

\subsection{Validation of small-signal model}

For the purpose of validating the developed small-signal model (Fig 4, the response of the model is compared with the Simulink model. The system parameter, detailed in Table 1 for PMSG 1, are used for both simulink and small-signal models.

The power factor (PF) of the load is maintained at 0.9 lagging PF all through the paper. Fig. 5 shows the system response of both models for a step change in load. The variables $P, Q, V$ and $f$ respectively represent the active power, reactive power, voltage and frequency. The signals from the Simulink and small-signal model are identified by the suffix "sim" and "mod" respectively. From Fig. 4a and Fig. 4c, it is observed that for an increase in active power demand from $0.32 \mathrm{pu}$ to $0.4 \mathrm{pu}, P_{\text {mod }}$ closely matches $P_{\text {sim }}$, while $f_{\text {mod }}$ also matches $f_{\text {sim }}$ but with a slightly higher undershoot than $f_{\text {sim }}$. Similarly, for an increase in reactive power demand from $0.16 \mathrm{pu}$ to $0.2 \mathrm{pu}$, Fig. $4 \mathrm{~b}$ and Fig. $4 \mathrm{~d}$ show that, $Q_{\text {mod }}$ closely matches $Q_{\text {sim }}$, while $V_{\text {mod }}$ also matches $V_{\text {sim }}$ but with slightly more oscillations. The results from Fig. 5 confirm that the developed model accurately represents the VSM. The increased oscillations observed on the small-signal model is due to the linearity of the system. 

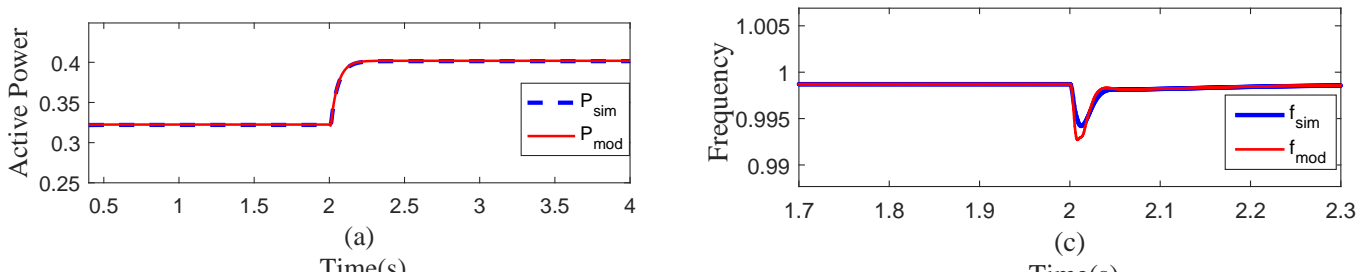

Time(s)
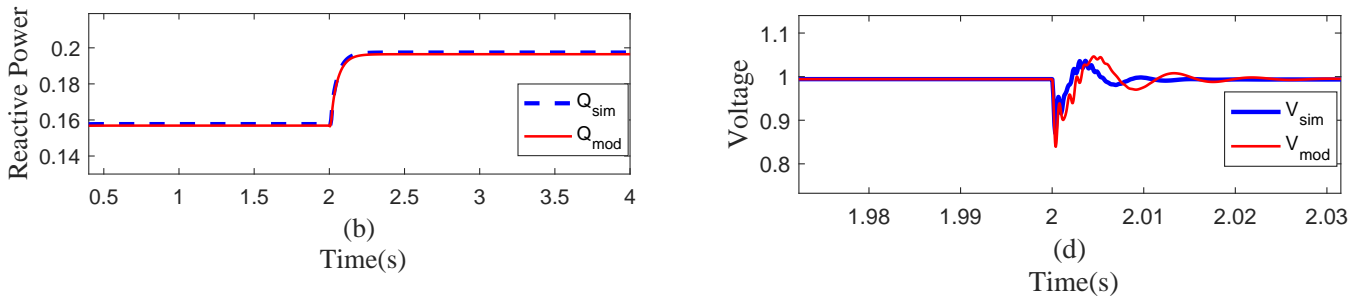

Figure 5: Simulation results comparing the response of the Simulink Model with the small-signal model:(a) Active Power (b) Reactive Power (c) Frequency (d) Voltage

\subsection{Eigenvalue analysis}

The steady state initial condition for this analysis, is a single VSM (PMSG 1) feeding an $R L$ load of $0.70 \mathrm{pu}$. The system parameters are given in Table. 1. The complete state space matrix of the VSM has 12 states Appendix A. As observed in Table. 2, all eigenvalues have negative real parts, indicating stable operation. The dominant states, which are shown in Table. 2, are derived using the participation factor matrix 32 .

Table 1: SYSTEM'S PARAMETERS

\begin{tabular}{|lll|}
\hline \multicolumn{3}{|c|}{ MSC } \\
\hline Variable & PMSG 1 & PMSG 2 \\
\hline \hline Rated Power & $2 \mathrm{MW}$ & $1 \mathrm{MW}$ \\
Rated Voltage & $0.7 \mathrm{kV}$ & $0.7 \mathrm{kV}$ \\
Rated Rotor speed & $3.1 \mathrm{rad} / \mathrm{s}$ & $4.4 \mathrm{rad} / \mathrm{s}$ \\
Inertia Time constant & $3 \mathrm{~s}$ & $2 \mathrm{~s}$ \\
DC link Voltage & $2 \mathrm{kV}$ & $2 \mathrm{kV}$ \\
DC link Capacitance & $6 \mathrm{mF}$ & $4.5 \mathrm{mF}$ \\
\hline & $\mathrm{VSM}(\mathrm{GSC})$ & \\
\hline Transmission line impedance $Z_{T}$ & $R=0.16 \mathrm{~m} \Omega / \mathrm{km}$ & $L=0.1 \mathrm{mH} / \mathrm{km}$ \\
Current loop PI controllers & $K_{p c}=0.15$ & $K_{i c}=1.5$ \\
PMS damping & $\tau_{f}=1.3 \mathrm{~s}$ & $\tau_{v}=0.005 \mathrm{~s}$ \\
PLL (PMSG 1/ PMSG 2) & $K_{p}=0.05 / 0.03$ & $K_{i}=0.5 / 0.03$ \\
Filter impedance $\quad R_{c}=1.5 \mathrm{~m} \Omega$ & $L_{c}=0.15 \mathrm{mH}$ & $C_{c}=160 \mu \mathrm{F}$ \\
\hline
\end{tabular}


Table 2: Complete System eigenvalues

\begin{tabular}{|c|c|c|c|c|c|}
\hline \multicolumn{3}{|c|}{ Eigenvalues } & \multirow{2}{*}{$\begin{array}{l}\text { Damping } \\
\text { ratio }(\zeta)\end{array}$} & \multirow[t]{2}{*}{$f(\mathrm{~Hz})$} & \multirow{2}{*}{$\begin{array}{l}\text { Dominant } \\
\text { states }\end{array}$} \\
\hline$\lambda$ & Real & Imaginary & & & \\
\hline$\lambda_{1}$ & 0 & & 1 & & $\Delta \delta$ \\
\hline$\lambda_{2,3}$ & -407 & $\pm 9910 \mathrm{i}$ & 0.04 & 1577 & $\Delta i_{c d q}, \Delta V_{c d q}, \Delta i_{l d q}$ \\
\hline$\lambda_{4}$ & -948 & & 1 & & $\Delta i_{c d}, \Delta i_{l d q}$ \\
\hline$\lambda_{5,6}$ & -441 & $\pm 8120 \mathrm{i}$ & 0.05 & 1292 & $\Delta i_{c d q}, \Delta V_{c d q}, \Delta i_{l d q}$ \\
\hline$\lambda_{7,8}$ & -410 & $\pm 1010 \mathrm{i}$ & 0.38 & 161 & $\Delta i_{c q}^{*}, \Delta i_{c q}, \Delta i_{l q}$ \\
\hline$\lambda_{9}$ & -40.1 & & 1 & & $\Delta i_{c d}^{*}$ \\
\hline$\lambda_{10}$ & -15.2 & & 1 & & $\Delta \alpha_{P L L}, \Delta i_{c d}^{*}, \Delta \gamma_{d q}$ \\
\hline$\lambda_{11,12}$ & -9.39 & $\pm 1.01 \mathrm{i}$ & 0.99 & 0.16 & $\Delta \alpha_{P L L}, \Delta \gamma_{q}$ \\
\hline
\end{tabular}

It can be inferred that there is a degree of coupling between the states relating to the active and reactive power control, this is because the system is not purely inductive [33. The zero eigenvalue $\lambda_{1}$, is due to the PLL angle $\Delta \delta$, a similar occurrence is observed with rotor angle when SGs are operated in islanded mode 32]. The super-synchronous oscillatory modes $\lambda_{2,3}$ and $\lambda_{5,6}$ are associated with the $L C$ filter and load, and are damped instantaneously $(0.003 \mathrm{~s})$. The modes $\lambda_{7,8}$ are mainly influenced by the virtual AVR, which dictates the reactive power flow.

The sub-synchronous oscillatory modes $\lambda_{11,12}$ are associated with states from the PLL and the current controller. The result of the eigenvalue analysis confirms that the VSM is well damped, as the dominant modes have a damping ratio, $\zeta \geq 5 \%$ [34]. The dominant modes of the VSM, which are $\lambda_{10}$ and $\lambda_{11,12}$, are mainly influenced by the reactive power flow and by states from the PLL and virtual governor. Hence, to maintain stability and achieve the desired dynamic performance of the VSM in all operating modes, the design parameters of the PLL, virtual AVR and virtual governor will be further investigated.

\subsection{Impact of PLL on VSM stability}

The PLL bandwidth has a dominant effect on the stability of the VSM. Although a fast PLL is required for grid synchronization, it can greatly reduce stability, increase phase tracking error and lead to poor harmonics filtering [26, 35]. Hence, a compromise is required between a fast synchronizing PLL and a desirable dynamic performance. Fig. 6 shows the transition of the open loop poles as the proportional gain $K_{p}$ of the PLL is increased. As the poles move closer to the origin, the voltage waveforms becomes distorted. It can be observed that for $K_{p} \geq 3$, the VSM becomes unstable. This corroborates earlier works [25], 26] which stipulate that, for stable operation in islanded operation PLL bandwidth should be small.

To ensure stability in the event of fault, where large swings are expected in $V_{c q}$ this work proposes keeping $K_{p}$ at $\leq 10 \%$ of the critical $K_{p}$ value $\left(K_{p} \approx 3\right)$. 


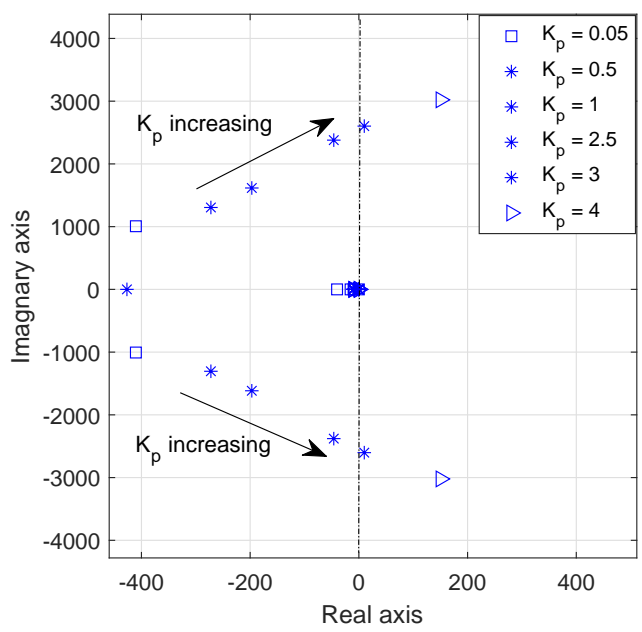

Figure 6: Transition of open loop poles with varying $K_{p}$

\subsection{Impact of Virtual AVR damping}

Based on the VSM design Fig. 3 , the voltage and frequency droop gains are constant (determined by the grid regulation in the region). However, the damping filter time constants $\tau_{f}$ and $\tau_{v}$ of the virtual governor and virtual AVR can be varied to improve the stability and transient response. Hence, the impact of $\tau_{f}$ and $\tau_{v}$ on the dynamics and transient stability of the VSM will be investigated using eigenvalue analysis and time domain simulation respectively.

Fig. 7a illustrates the transition of the poles as $\tau_{v}$ is varied. It is observed that as $\tau_{v}$ is increased, the open loop poles move towards the right half plane (RHP) indicating a less stable operating mode. For large values of $\tau_{v}\left(\tau_{v}>0.6\right)$ the open loop poles cross over to the Left hand plane and the system becomes unstable.

Fig. $7 \mathrm{~b}$ illustrates the transient performance of the proposed VSM for different values of $\tau_{v}$ (at the same operating point as the linearized model used for the eigenvalue analysis). The VSM is initially gridconnected, a 3-phase fault is applied on the grid side at $2.86 \mathrm{~s}$, and the VSM is disconnected at $3 \mathrm{~s}$ and operates in islanded mode. It can be observed that as the damping on the virtual AVR is increased, which results in a slower response, the transient performance worsens and for $\tau_{v}=0.1$ the VSM fails to recover post-fault. This results corroborate the result from the small signal analysis, which shows that increasing $\tau_{v}$ moves the VSM poles towards unstable region. Hence, this work proposes keeping $\tau_{v}$ at $\leq 0.01$. This findings also conforms with the operation of the $\mathrm{SG}$, where high exciter response is required to increase synchronizing torque and improve transient stability [32]. 


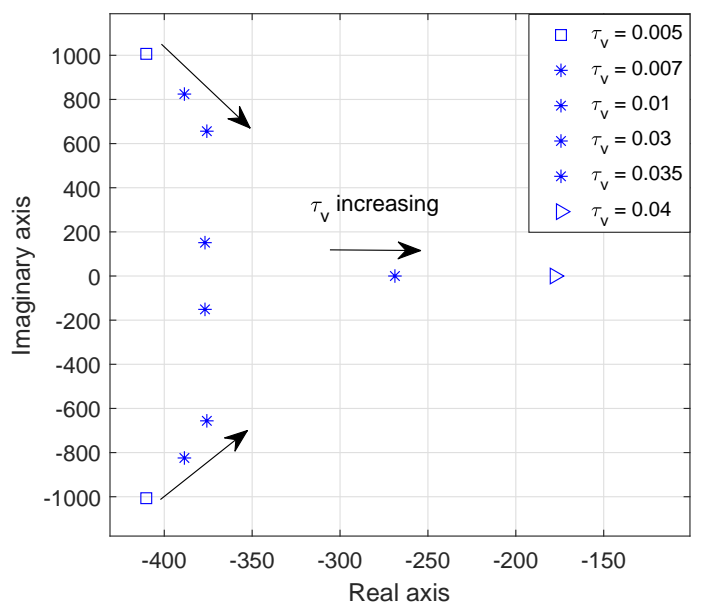

(a) Transition of open loop poles with varying $\tau_{v}$

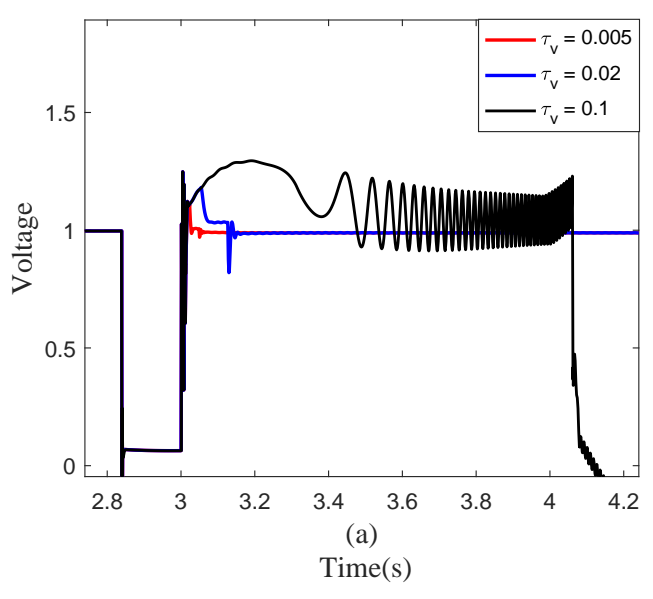

(b) Transient performance of VSM for varying values of $\tau_{v}$

Figure 7: Performance of VSM for different values of $\tau_{v}$

\subsection{Impact of Virtual Governor damping}

The damping filter time constant $\tau_{f}$ of the virtual governor is directly proportional to the magnitude of the VSM inertia [19. Fig. 8, illustrates the transition of the open loop poles as $\tau_{f}$ is varied. It can be observed that the open loop poles drift away from the RHP as $\tau_{f}$ increases, indicating a more stable operation. Furthermore, an increase in $\tau_{f}$ results in damping of higher frequency oscillations in the system.

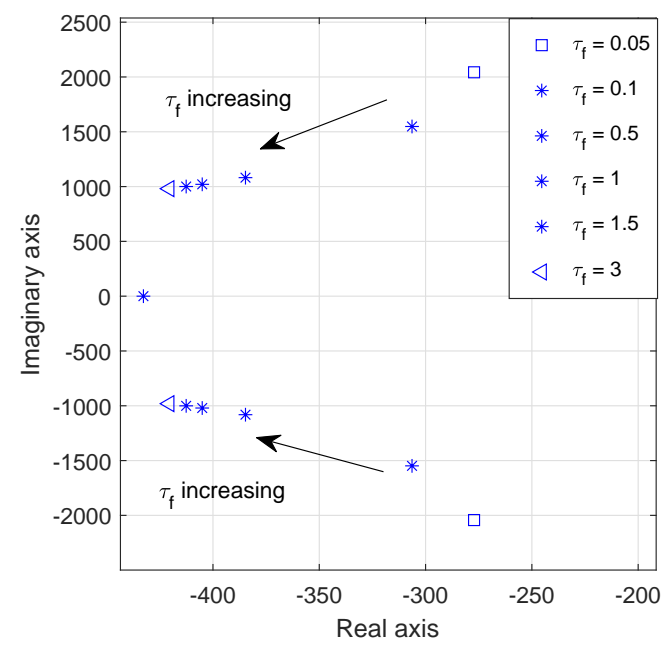

Figure 8: Transition of open loop poles with varying $\tau_{f}$ 
To observe the transient stability of the VSM due to $\tau_{f}$, the same test procedure as for Fig. 7 is implemented. As it can be seen from Fig. 9, after the fault is cleared, we observe a relatively high frequency oscillation on the voltage signal for $\tau_{f}=0.2$, indicating an underdamped system. However for $\tau_{f} \geq 0.4$, the VSM provides a better damped response which suppresses the oscillation due to the disturbance and eliminates high frequency oscillation caused by the PLL interaction with the controllers. Despite the benefits of a large inertia, a very slow system response is also undesirable. Hence, this work proposes keeping $\tau_{f}$ at, $0.4 \leq \tau_{f} \leq 1.5$. This phenomenon is also similar to the SG, where a large inertia is required to mitigate disturbances and sufficient damping of the rotor angle is required to maintain stability after a large disturbance 32 .

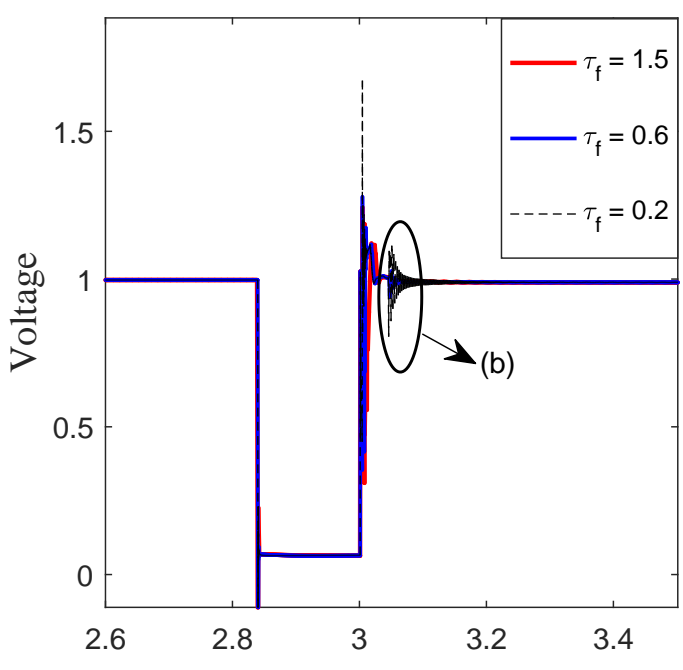

(a)

Time(s)

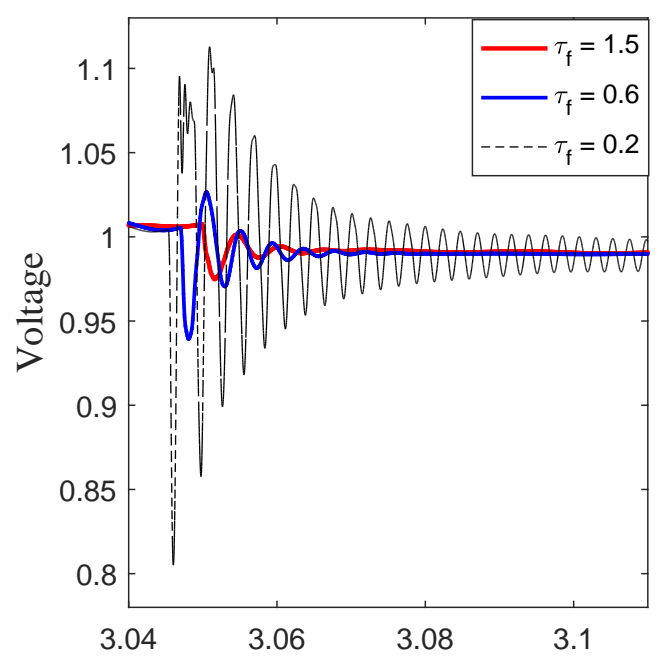

(b)

Time(s)

Figure 9: Transient response of VSM for different values of $\tau_{f}$

\section{SIMULATION AND DISCUSSION}

The model shown in Fig. 1] is simulated in MATLAB/SIMULINK environment. The system parameters for the PMSGs are given in Table 1. All results are presented in pu based on total system rating (not each PMSG). The output of the individual PMSGs are represented as PMSG1 and PMSG2. $P_{T}, Q_{T}$ and $P_{\text {grid }}, Q_{\text {grid }}$ represent the total active and reactive power from the PMSGs and the grid respectively. $\omega_{o p t}$ represents the optimal rotor speed based on available wind power, while $\omega_{r 1}$ and $\omega_{r 2}$ represents the rotor speed of each PMSG. 
Figs. 9.g and 9.h illustrate the voltage and frequency at PCC (see Fig. 1). Fig. 10 illustrates the simulation results of the following scenarios:

\subsection{Grid Operation (0-10 s)}

The simulation starts with the two PMSGs connected to the grid. It can be observed from Fig. 9.a that the PMSGs are operating at MPPT as $\omega_{o p t}=\omega_{r 1}=\omega_{r 2}=0.78 \mathrm{pu}$. The surplus power (not consumed by $P_{L}$ ) is transferred to $P_{\text {grid }}$ (Fig. 9.c). It is also observed (Figs. 9.d and 9.e) that $Q_{L}$ is supplied by the grid, which is in compliance with the control paradigm. At $\mathrm{t}=2.84 \mathrm{~s}$, a 3 -phase fault occurs at the grid side, (see Fig. 1). The PMSGs seamlessly rides through the fault, as the DC voltage $V_{d c}$ (Fig. 9.e) and $f$ (Fig. 9.g) are well regulated. It is worth noting that, unlike conventional control strategies (where $V_{d c}$ is controlled by GSC) 21, $V_{d c}$ does not rise during fault, as the prime mover (MSC) only supplies the power demanded from the VSM. Hence $P_{e} \approx P_{g}$ during fault, and the surplus energy from the wind during fault is stored as kinetic energy (K.E) in the rotor ( $\omega_{r 1}$ and $\omega_{r 2}$ increases). This eliminates the need for crowbar on the DC-link to dissipate excess energy. As observed from Fig. 11 there is minimal distortion on the voltage waveform during the fault. The fault is cleared at $3 \mathrm{~s}$, and it is observed that the VSM maintains stable operation; as instability due to large disturbance is usually evident within 2 to 3 seconds after the disturbance 32. At $\mathrm{t}=10 \mathrm{~s}$, the VSM is disconnected from the grid. Unlike [18, there is no need to switch controllers when disconnecting the VSM from the grid. As observed from Fig. 10, the transition to islanded operation is seamless.

\subsection{Islanded operation (10-100 s)}

In this operating mode, the PMS ensures $V$ and $f$ are regulated within nominal values, hence the PMSGs operate in the sub-optimal power region (which is reflected by an increase in the rotor speeds) 36. determined by the load demand. The following test scenarios are applied in this mode:

A step reduction in load demand occurs at $\mathrm{t}=30 \mathrm{~s}$. As illustrated in Figs. 9.c and 9.e, $P_{T}$ and $Q_{T}$ precisely follow the change in load demand $P_{L}$ and $Q_{L}$ respectively. As shown in Figs. 9.b and 9.d, the load is shared by the two PMSGs while the surplus electrical power in the PMSGs are stored as K.E in the rotor.

The microgrid runs smoothly until $t=50 \mathrm{~s}$, when PMSG 2 is suddenly taken offline (CB 2 is open). Upon the sudden loss of PMSG 2, PMSG 1 supplies the total load. As observed from Fig. 9.a PMSG1 releases the stored K.E and operates close to the MPPT region. Since PMSG2 is operating on no-load, the pitch control is automatically activated to limit $\omega_{r 2}$ to $1.2 \mathrm{pu}$. The standard pitch control from MATLAB was implemented here. As observed from Fig. 9.g and 9.h, $V$ and $f$ are well regulated and the system maintains stability despite the large disturbance. This shows that, for a microgrid implementing the proposed VSM, if one or more converters develop a fault during operation, it can be easily taken offline with negligible 


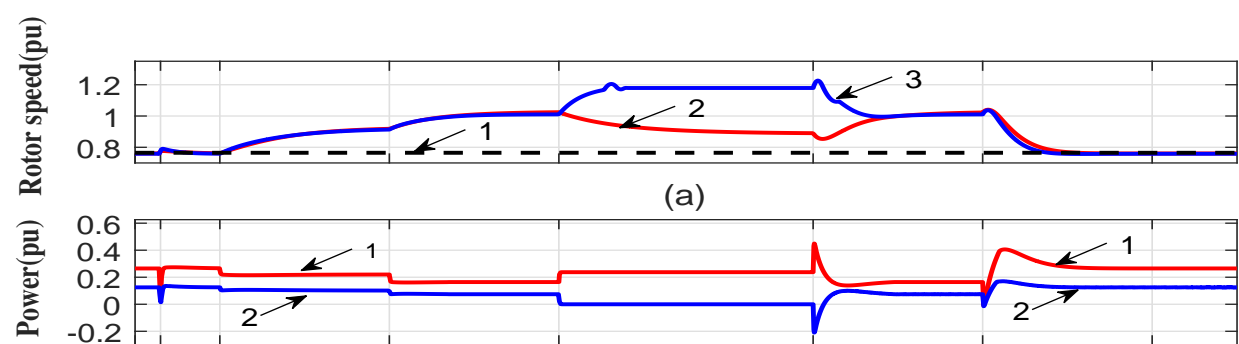

(b)
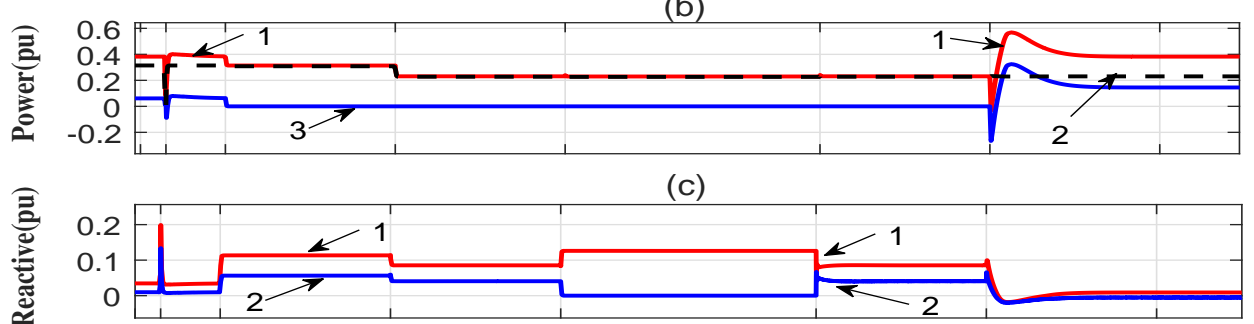

(d)

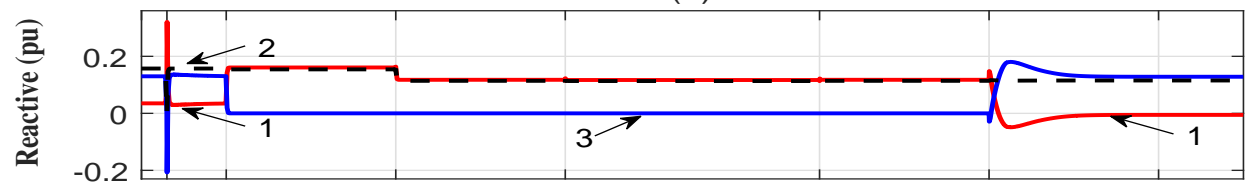

(e)

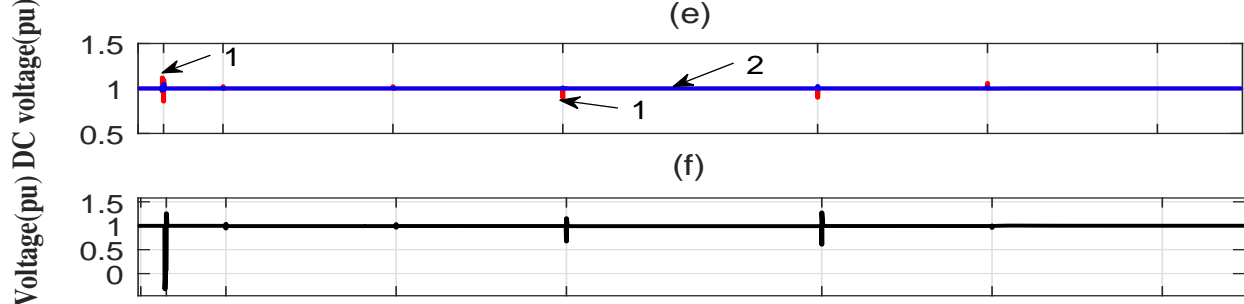

(g)

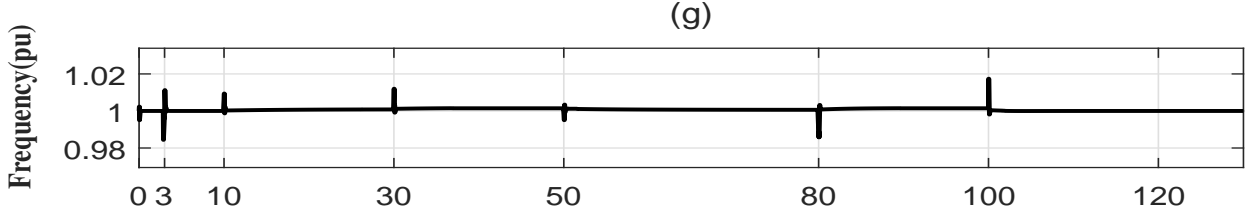

(h)

Time (s)

Figure 10: Simulation results for PMSGs in grid-connected and islanded mode:(a) Rotor speed, pu 1- $\omega_{o p t}, 2-\omega_{r 1}$, 3 - $\omega_{r 2}$. (b) Power, pu 1 - PMSG1, 2 - PMSG2. (c) Power, pu 1 - $P_{T}, 2$ - $P_{L}, 3$ - $P_{g r i d}$ (d) Reactive power, 1 $P M S G 1,2$ - PMSG2 (e) Reactive power, pu $1-Q_{T}, 2-Q_{L}, 3-Q_{\text {grid }}$ (f) DC-Link voltage ( $V_{d c}$ ), pu 1 - PMSG1, 2 - PMSG2 (g) Voltage at PCC, pu (h) Frequency at PCC, pu. 


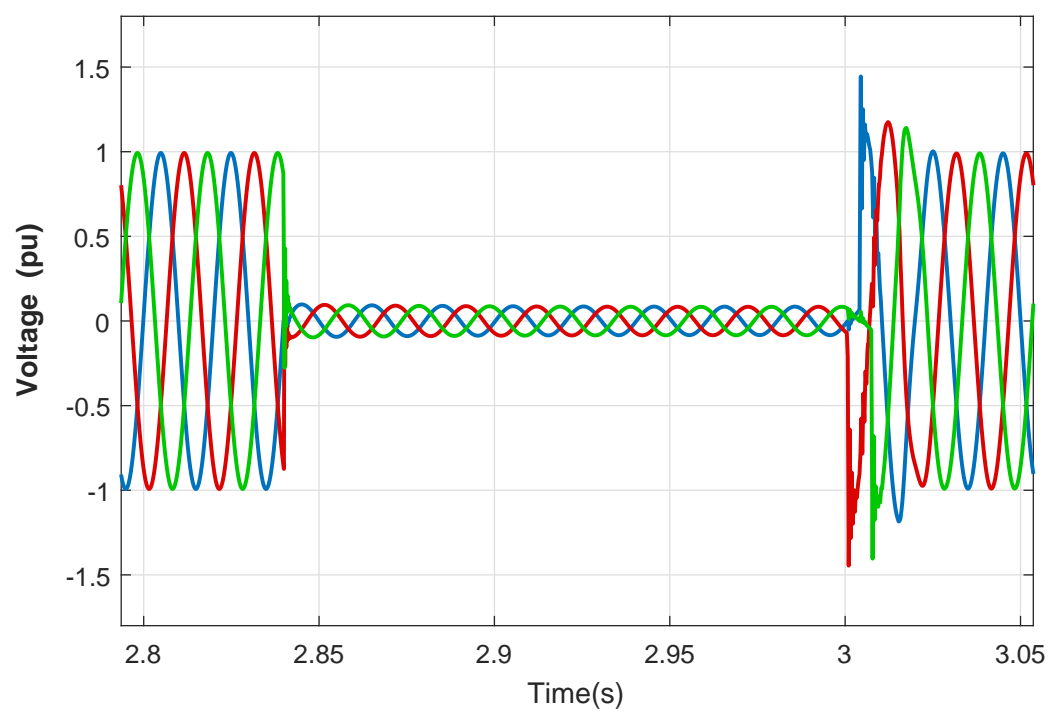

Figure 11: The three-phase voltage waveform at PCC (pu) for the fault duration

impact on the operation of the remaining VSMs. At $\mathrm{t}=80 \mathrm{~s}$, PMSG 2 is reconnected and the load is shared between the two PMSGs. Fig. 10 shows that $V$ and $f$ are maintained within nominal value.

\subsection{Grid Reconnection (100-130 s)}

At $\mathrm{t}=100 \mathrm{~s}$, the grid is restored and CB 3 is closed. The transition to the grid is relatively smooth, and $V$ and $f$ are well controlled. As observed from Fig. 10, there is negligible voltage oscillation during transition to grid, as the phase difference between the microgrid and the grid at the time of closing CB3 is very minute. As earlier discussed a fast PLL will be detrimental to system stability. However, since grid reconnection is always intentional, conventional industry techniques 37] can be applied prior to closing CB 3 to ensure smooth transition to grid.

\section{Conclusion}

This paper proposed a VSM strategy for PMSG based wind turbines, which enables seamless operation in grid and islanded operation. It achieves MPPT in grid-connected operation, LFPG in islanded operation and LVRT during faults.

A detailed mathematical model of the VSM was derived and the dynamic response was validated with the Simulink model. The derived model was analyzed in the event of small and large perturbations. It was observed from the analysis, that a low PLL bandwidth is required for a desirable performance and stable 
operation of the VSM. It was also observed that, a fast virtual AVR and a relatively slow and well damped virtual governor are essential to maintain stability and optimal dynamic performance.

The results of this analysis, were used as a guide in the design of the VSM. To verify the performance of the VSM, a time domain simulation (MATLAB/SIMULINK) was performed for different test scenarios. The results confirmed that the VSM operates seamlessly in grid-connected and islanded modes, and rides through fault without switching controls in all modes.

Future research work will consider parallel operation of the VSM with Synchronous Generators, investigating inter-area oscillations and the network stability.

\section{Acknowledgements}

The support from the FLEXIS project, which is part-funded by the European Regional Development Fund through the Welsh Government, is acknowledged.

\section{Appendix A.}

$$
\begin{aligned}
& \frac{d}{d t} X=\mathbf{A}[\Delta X]+\mathbf{B}[\Delta U] \\
& \Delta X=\left[\begin{array}{lllllll}
\Delta \delta & \Delta \alpha_{P L L} & \Delta i_{c d q}^{*} & \Delta \gamma_{o d q} & \Delta i_{c d q} & \Delta v_{c d q} & \Delta i_{l d q}
\end{array}\right]^{T} \\
& \mathbf{A}=\left[\begin{array}{cccc}
A_{P L L} & 0 & 0 & {\left[\begin{array}{c}
B_{P L L} \\
B_{P M S_{f}} C_{P L L} \\
B_{P M S_{v}} \\
B_{P M S_{f}} D_{P L L}
\end{array}\right]} \\
B_{L C L 2}(k i) & B_{L C L 1} D_{c 1} & B_{L C L 1} C_{c} & A_{L C L}+B_{L C L 1} D_{c 2} \\
& & & +B_{L C L 2}(k p)
\end{array}\right]_{12 \times 12} \\
& \mathbf{B}=\left[\begin{array}{llll}
0 & B_{P M S_{v}} & 0 & 0 \\
0 & B_{P M S_{f}} & 0 & 0
\end{array}\right]_{2 \times 12} \quad, \Delta U=\left[\begin{array}{ll}
\Delta V_{c d}^{*} & \Delta f^{*}
\end{array}\right]
\end{aligned}
$$




\section{References}

[1] Q. Zhong, G. Weiss, Synchronverters: Inverters that mimic synchronous generators, IEEE Transactions on Industrial Electronics 58 (4) (2011) 1259-1267 (April 2011). doi:10.1109/TIE.2010.2048839.

[2] R. Smith, System operability framework, Tech. rep., National Grid (UK) (2016).

[3] A. Fathi, Q. Shafiee, H. Bevrani, Robust frequency control of microgrids using an extended virtual synchronous generator, IEEE Transactions on Power Systems 33 (6) (2018) 6289-6297 (Nov 2018). doi:10.1109/TPWRS.2018.2850880.

280

[4] A. J Roscoe, M. Yu, A. Dyśko, C. Booth, R. Ierna, J. Zhu, H. Urdal, A vsm (virtual synchronous machine) convertor control model suitable for rms studies for resolving system operator / owner challenges, 15th Wind Integration Workshop (November 2016).

URL http://strathprints.strath.ac.uk/58053/

[5] H. T. Nguyen, G. Yang, A. H. Nielsen, P. H. Jensen, Frequency stability improvement of low inertia systems using synchronous condensers, in: 2016 IEEE International Conference on Smart Grid Communications (SmartGridComm), 2016, pp. 650-655 (Nov 2016). doi:10.1109/SmartGridComm.2016. 7778835

[6] F. S. AL-Ismail, M. A. Hassan, M. A. Abido, Rtds implementation of statcom-based power system stabilizers, Canadian Journal of Electrical and Computer Engineering 37 (1) (2014) 48-56 (2014). doi:10.1109/CJECE.2014.2309323.

[7] A. Movahedi, A. H. Niasar, G. Gharehpetian, Designing sssc, tcsc, and statcom controllers using avurpso, gsa, and ga for transient stability improvement of a multi machine power system with pv and wind farms, International Journal of Electrical Power and Energy Systems 106 (2019) 455 - 466 (2019). doi:https://doi.org/10.1016/j.ijepes.2018.10.019R

URL http://www.sciencedirect.com/science/article/pii/S0142061517331447

[8] L. Wang, Z. Yang, X. Lu, A. V. Prokhorov, Stability analysis of a hybrid multi-infeed hvdc system connected between two offshore wind farms and two power grids, IEEE Transactions on Industry Applications 53 (3) (2017) 1824-1833 (May 2017). doi:10.1109/TIA.2017.2672669

[9] A. Yazdani, R. Iravani, Voltage-Sourced Converters in Power Systems:Modeling, Control, and Applications, IEEE, 2010 (2010). 
[10] J. Zhu, J. Hu, W. Hung, C. Wang, X. Zhang, S. Bu, Q. Li, H. Urdal, C. D. Booth, Synthetic inertia control strategy for doubly fed induction generator wind turbine generators using lithiumion supercapacitors, IEEE Transactions on Energy Conversion 33 (2) (2018) 773-783 (June 2018). doi:10.1109/TEC.2017.2764089

[12] S. Wang, J. Hu, X. Yuan, L. Sun, On inertial dynamics of virtual-synchronous-controlled dfig-based

[16] U. Tamrakar, D. Shrestha, M. Maharjan, B. P. Bhattarai, T. M. Hansen, R. Tonkoski, Virtual inertia: Current trends and future directions, Applied Sciences 7 (7) (2017). doi:10.3390/app7070654 URL https ://www .mdpi.com/2076-3417/7/7/654

[17] J. Liu, Y. Miura, H. Bevrani, T. Ise, Enhanced virtual synchronous generator control for parallel 325

[18] K. S. Yuko Hirase, Kazuhiro Abe, Y. Shindo, A grid-connected inverter with virtual synchronous generator model of algebraic type, IEEJ Transactions on Power and Energy 132 (2012) 371-380 (2012). doi:https://doi.org/10.1541/ieejpes.132.371 
19] M. Fazeli, P. Holland, Universal and seamless control of distributed resources-energy storage for all operational scenarios of microgrids, IEEE Transactions on Energy Conversion 32 (3) (2017) 963-973 (Sept 2017). doi:10.1109/TEC.2017.2689505

[20] M. Mueller, Electrical Drives for Direct Drive Renewable Energy Systems, Woodhead Publishing Series 1) in Energy, Woodhead Publishing, 2013 (2013). doi:https://doi.org/10.1016/B978-1-84569-783-9. 50014-6

URL http://www.sciencedirect.com/science/article/pii/B9781845697839500146

[21] O. P. Mahela, N. Gupta, M. Khosravy, N. Patel, Comprehensive overview of low voltage ride through methods of grid integrated wind generator, IEEE Access 7 (2019) 99299-99326 (2019). doi:10.1109/ ACCESS.2019.2930413

[22] M. Nasiri, J. Milimonfared, S. Fathi, A review of low-voltage ride-through enhancement methods for permanent magnet synchronous generator based wind turbines, Renewable and Sustainable Energy Reviews 47 (2015) 399 - 415 (2015). doi:https://doi.org/10.1016/j.rser.2015.03.079

URL http://www .sciencedirect.com/science/article/pii/S1364032115002324

[23] J. I. Yoo, J. Kim, J. Park, Converter control of pmsg wind turbine system for inertia-free stand-alone microgrid, in: 2016 IEEE Industry Applications Society Annual Meeting, 2016, pp. 1-8 (Oct 2016). doi:10.1109/IAS.2016.7731830

[24] G. Li, Z. Du, T. An, Y. Xia, J. Lei, Impact of pll and vsc control parameters on the ac/mtdc systems stability, Electric Power Systems Research 141 (2016) 476 - 486 (2016). doi:10.1016/j.epsr.2016. 08.030

[25] C. Zhang, X. Wang, F. Blaabjerg, Analysis of phase-locked loop influence on the stability of singlephase grid-connected inverter, in: 2015 IEEE 6th International Symposium on Power Electronics for Distributed Generation Systems (PEDG), 2015, pp. 1-8 (June 2015). doi:10.1109/TIE.2014.2334665

[26] X. Guo, S. Liu, X. Wang, Impact of phase-locked loop on stability of active damped lcl-filter-based grid-connected inverters with capacitor voltage feedback, Journal of Modern Power Systems and Clean

[27] X. Hou, Y. Sun, W. Yuan, H. Han, C. Zhong, J. M. Guerrero, Conventional p-w/q-v droop control in en9110943 
[28] T. V. Hoang, H. Lee, An adaptive virtual impedance control scheme to eliminate the reactive-powersharing errors in an islanding meshed microgrid, IEEE Journal of Emerging and Selected Topics in Power Electronics 6 (2) (2018) 966-976 (June 2018). doi:10.1109/JESTPE. 2017.2760631

[29] Y. Han, H. Li, P. Shen, E. A. A. Coelho, J. M. Guerrero, Review of active and reactive power sharing strategies in hierarchical controlled microgrids, IEEE Transactions on Power Electronics 32 (3) (2017) 2427-2451 (March 2017). doi:10.1109/TPEL.2016.2569597.

[30] Y. A. I. Mohamed, E. F. El-Saadany, Adaptive decentralized droop controller to preserve power sharing stability of paralleled inverters in distributed generation microgrids, IEEE Transactions on Power Electronics 23 (6) (2008) 2806-2816 (Nov 2008). doi:10.1109/TPEL.2008.2005100.

[31] A. E. M. Bouzid, P. Sicard, A. Yamane, J. Paquin, Simulation of droop control strategy for parallel inverters in autonomous ac microgrids, in: 2016 8th International Conference on Modelling, Identification and Control (ICMIC), 2016, pp. 701-706 (Nov 2016). doi:10.1109/ICMIC.2016.7804202.

[32] P. Kundur, N. Balu, M. Lauby, Power System Stability and Control, McGraw-Hill Education, 1994 (1994).

[33] N. Pogaku, M. Prodanovic, T. C. Green, Modeling, analysis and testing of autonomous operation of an inverter-based microgrid, IEEE Transactions on Power Electronics 22 (2) (2007) 613-625 (March 2007). doi:10.1109/TPEL.2006.890003

[34] O. Kotb, M. Ghandhari, R. Eriksson, V. K. Sood, On small signal stability of an ac/dc power system with a hybrid mtdc network, Electric Power Systems Research 136 (2016) 79 - 88 (2016). doi: $10.1016 / j . e p s r .2016 .02 .004$.

[35] S.-K. Chung, A phase tracking system for three phase utility interface inverters, IEEE Transactions on Power Electronics 15 (3) (2000) 431-438 (May 2000). doi:10.1109/63.844502

[36] Y. Tan, L. Meegahapola, K. M. Muttaqi, A suboptimal power-point-tracking-based primary frequency response strategy for dfigs in hybrid remote area power supply systems, IEEE Transactions on Energy Conversion 31 (1) (2016) 93-105 (March 2016). doi:10.1109/TEC.2015.2476827.

[37] R. A. Allah, Correlation-based synchro-check relay for power systems, IET Generation, Transmission Distribution 12 (5) (2018) 1109-1120 (2018). doi:10.1049/iet-gtd.2017.0448. 